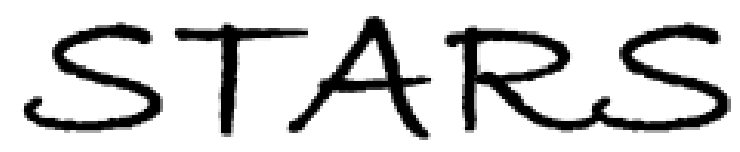

University of Central Florida

STARS

$1-1-2005$

\title{
Size dependency variation in lattice parameter and valency states in nanocrystalline cerium oxide
}

\author{
Sameer Deshpande \\ University of Central Florida \\ Swanand Patil \\ University of Central Florida \\ Satyanarayana VNT Kuchibhatla \\ University of Central Florida \\ Sudipta Seal \\ University of Central Florida
}

Find similar works at: https://stars.library.ucf.edu/facultybib2000

University of Central Florida Libraries http://library.ucf.edu

This Article is brought to you for free and open access by the Faculty Bibliography at STARS. It has been accepted for inclusion in Faculty Bibliography 2000s by an authorized administrator of STARS. For more information, please contactSTARS@ucf.edu.

\section{Recommended Citation}

Deshpande, Sameer; Patil, Swanand; Kuchibhatla, Satyanarayana VNT; and Seal, Sudipta, "Size dependency variation in lattice parameter and valency states in nanocrystalline cerium oxide" (2005). Faculty Bibliography 2000s. 5121.

https://stars.library.ucf.edu/facultybib2000/5121

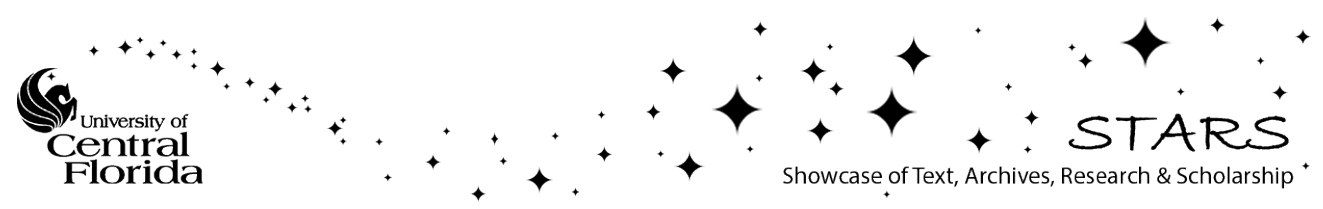




\title{
Size dependency variation in lattice parameter and valency states in nanocrystalline cerium oxide
}

\author{
Sameer Deshpande, Swanand Patil, Satyanarayana VNT Kuchibhatla, and Sudipta Seal ${ }^{\mathrm{a})}$ \\ Advanced Material Processing and Analysis Center (AMPAC), Mechanical, Materials, and Aerospace \\ Engineering, University of Central Florida, 4000 Central Florida Boulevard, Orlando, Florida 32816
}

(Received 24 May 2005; accepted 4 August 2005; published online 22 September 2005)

A correlation between the particle size and the lattice parameter has been established in nanocerium
oxide particles $(3-30 \mathrm{~nm})$. The variation in the lattice parameter is attributed to the lattice strain
induced by the introduction of $\mathrm{Ce}^{3+}$ due to the formation of oxygen vacancies. Lattice strain was
observed to decrease with an increase in the particle size. Ce $\mathrm{Ce}^{3+}$ ions concentration increased from
$17 \%$ to $44 \%$ with the reduction in the particle size. (C) 2005 American Institute of Physics.
[DOI: $10.1063 / 1.2061873$ ]

A substantial difference in the properties of nanomaterials, compared to their bulk counterparts, is attributed to the enhanced surface area to volume ratio, quantum confinement, and changes in the lattice parameter and symmetry. ${ }^{1}$ Recently, there has been an increased interest in nanocrystalline cerium oxide (ceria, $\mathrm{CeO}_{2}$ ) due to its wide range of applications. $^{2-5}$ The ability to absorb and release oxygen plays a critical role in the overall performance of the catalytic activity of ceria. This is due to the change in the oxidation state of $\mathrm{Ce}$ between $\mathrm{Ce}^{3+}$ and $\mathrm{Ce}^{4+}$ depending on the oxygen partial pressure in the surrounding atmosphere.

The present study was aimed at determining the impact of particle size on the lattice parameter and the surface chemistry variation in nanocrystalline ceria synthesized using wet chemical synthesis. ${ }^{6}$ The size and shape of the nanoparticles was determined using high-resolution transmission electron microscopy (HRTEM) (Philips Tecnai) at $300 \mathrm{kV}$.

Theoretical calculations showed that a (111) surface is the most stable surface among the low index planes of $\mathrm{CeO}_{2}{ }^{7}$ Figures $1(\mathrm{a})-1(\mathrm{c})$ showed that dominant fringes from ceria particles are (111). The ring patterns obtained in the selected area electron diffraction (SAED) patterns [shown as insets in Figs. 1(a)-1(c)] confirm the nanocrystallinity and the fluorite structure.

The lattice parameter of cerium oxide nanoparticles was measured using $\mathrm{x}$-ray diffraction (XRD) (Rigaku Model) with a $\mathrm{Cu} K \alpha_{1}$ radiation and the optimized operating conditions. Broad XRD peaks [Fig. 1(d)] indicate the nanocrystalline nature of the particles.

Figure 2(a) shows the effect of the crystallites' size, " $D$ " on the lattice parameter, " $a$," of the synthesized ceria nanoparticles. It can be observed that the reduction in the particle size leads to an increase in the lattice parameter. From Fig. 1, it can be concluded that the lattice expansion of ceria nanoparticles are primarily dependant on the particle size. Figure 2(b) shows a log-log plot of the lattice parameter variation $\left(\Delta a=a-a_{0}\right)$ and the particle size, where $a_{0}$ is the lattice parameter of the bulk $\mathrm{CeO}_{2}, 0.5410 \mathrm{~nm}$. From Fig. 2(b), we can obtain the following relationship between $\Delta a$ and the particle size as:

$$
\log (\Delta a)=-0.4763 \log (D)-1.5029
$$

\footnotetext{
${ }^{a)}$ Electronic mail: sseal@mail.ucf.edu
}

$$
\begin{aligned}
& \text { Simplifying, } \\
& \Delta a=0.031 D^{-0.4763,}
\end{aligned}
$$

where $D$ is the particle size of the nanoceria particles. This relation obtained above is valid for all the particle sizes.

Zou et $a l^{8}{ }^{8}$ suggested that the variation in the lattice parameter occurs due to the surface stress on ceria crystals. This stress transpires due to hydrogen bonding between adsorbed hydrogen atoms in the solution with oxygen atoms within the lattice. In the present situation, $\mathrm{H}_{2} \mathrm{O}_{2}$ was used as an oxidizing agent for synthesizing the ceria nanoparticles. $\mathrm{H}_{2} \mathrm{O}_{2}$ is very unstable even at normal conditions and, after adding to the solutions, it dissociates and produces the perhydroxyl ions $\left(\mathrm{HOO}^{-}\right)$(Ref. 9) which further reacts with the $\mathrm{Ce}^{4+}$ ions as shown. This causes the reduction of $\mathrm{Ce}^{4+}$ and an oxygen vacancy is created:

$$
\begin{aligned}
& \mathrm{H}_{2} \mathrm{O}_{2}+\mathrm{OH}^{-} \rightarrow \mathrm{HOO}^{-}+\mathrm{H}_{2} \mathrm{O}, \\
& \mathrm{Ce}^{4+}+\mathrm{HOO}^{-} \rightarrow \mathrm{Ce}^{3+}+\mathrm{O}_{2}+\mathrm{H}^{+} .
\end{aligned}
$$

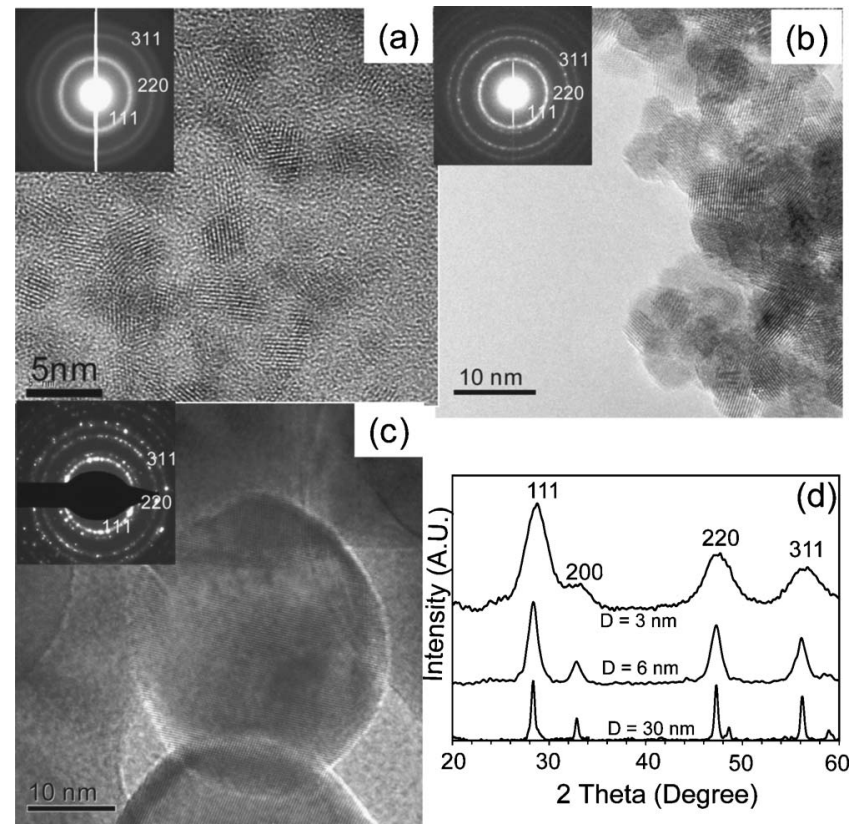

FIG. 1. HRTEM images of nanoceria with sizes of: (a) $3 \mathrm{~nm}$ (b) $6 \mathrm{~nm}$, and (c) $30 \mathrm{~nm}$. (Inset shows the SAED). (d) Comparative XRD spectra of different sized ceria nanoparticles. 

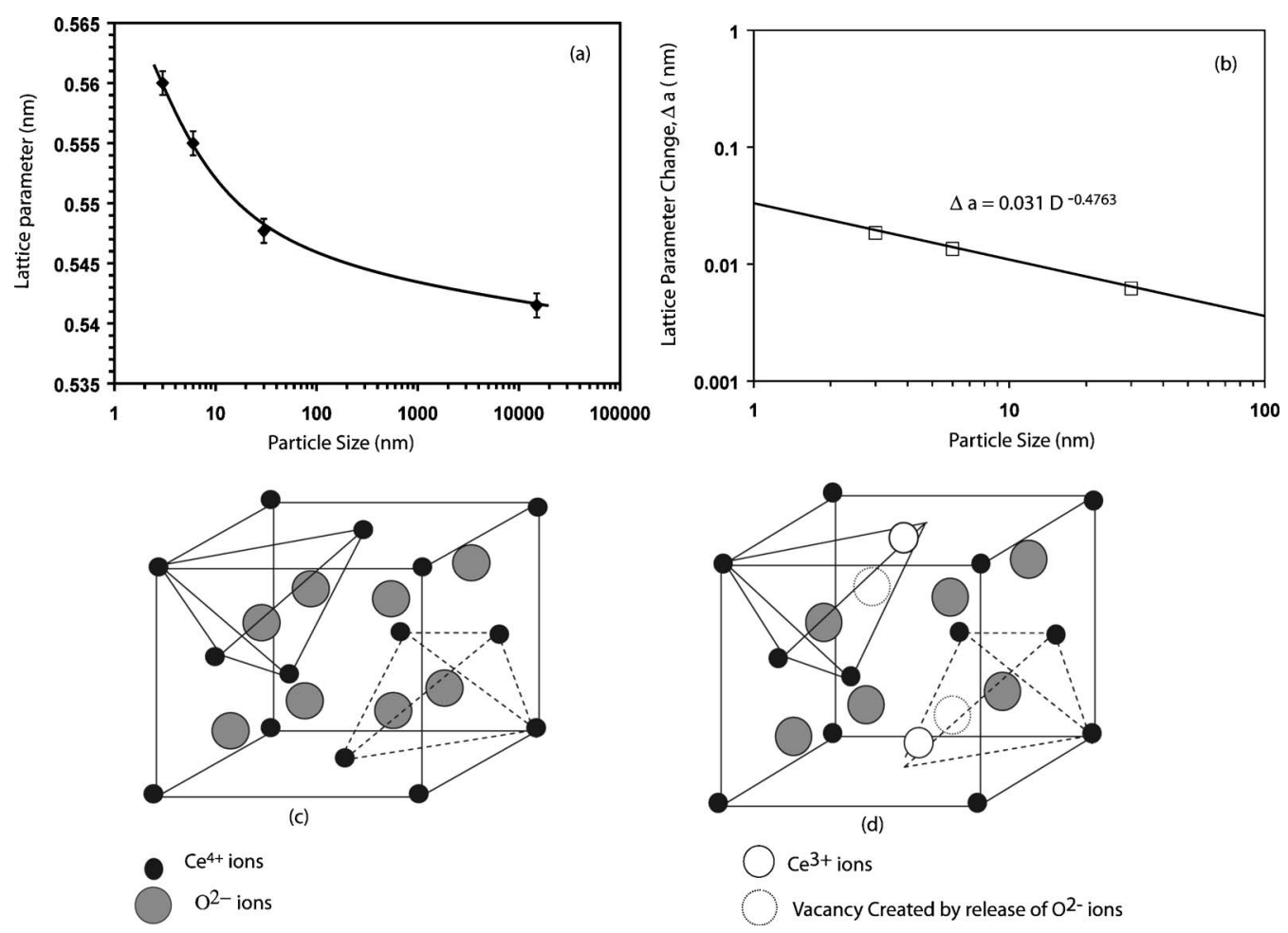

FIG. 2. (a) Semilog plot of the lattice parameter as a function of the particle size. (b) Log-log plot of the change in the lattice parameter vs particle size. (c) Cartoon diagram of bulk ceria crystal structure showing intact $\mathrm{CaF}_{2}$ structure. (d) Distorted crystal structure of nanoceria due to oxygen vacancy creation and replacement of $\mathrm{Ce}^{4+}$ ions by $\mathrm{Ce}^{3+}$ ions.

$\mathrm{CeO}_{2}$ crystallizes in the fluorite structure, in which $\mathrm{Ce}^{4+}$ cation is surrounded by eight equivalent $\mathrm{O}^{2-}$ ions forming the corner of a cube, with each $\mathrm{O}^{2-}$ coordinated to four $\mathrm{Ce}^{4+}$ as shown in Fig. 2(c). Due to the reaction given in Eq. (4), the coordination number of $\mathrm{Ce}^{4+}$ to $\mathrm{O}^{2-}$ reduces from eight to seven and introduces $\mathrm{Ce}^{3+}$ ions into the crystal lattice, as shown in Fig. 2(d). $\mathrm{Ce}^{3+}$ ions have a higher ionic radius $(1.034 \AA)$ as compared to the $\mathrm{Ce}^{4+}$ ions $(0.92 \AA)$. The introduction of the oxygen vacancies and the accompanying $\mathrm{Ce}^{3+}$ ions leads to a distortion of the local symmetry. This causes the change in the $\mathrm{Ce}-\mathrm{O}$ bond length (lattice distortion) and the overall lattice parameter.

The lattice strain in all the samples was calculated as shown in Fig. 3(a). It can be observed that there is a monotonous decrease in the lattice strain with increasing particle size. The high strain in the lattice may lead to lattice expansion in order to relieve the strain. In the case of large crystallites, the loss of few oxygen atoms does not produce much lattice strain and, hence, the lattice distortion observed is less. On the other hand, as the size reduces $(\sim 3 \mathrm{~nm})$, the loss of even one oxygen atom creates a very high lattice strain [Fig. 3(a)] and, hence, larger lattice relaxation is observed. Though the nanoparticles reduce the strain by lattice expansion, the relaxation is not complete and, therefore, the strain is observed as shown in Fig. 3(a).

In order to validate the changes in the nanoceria surface valence chemistry, $\mathrm{x}$-ray photoelectron spectroscopic (XPS) (PE-PHI5400) study was carried out on all the particles at optimized conditions. ${ }^{10}$ Figure 3(b) shows the deconvoluted XPS Ce $(3 d)$ spectrum for $3 \mathrm{~nm}$-sized ceria nanoparticles. In the figure, $v_{0}, v^{\prime}, u_{0}$, and $u^{\prime}$ peaks are attributed to $\mathrm{Ce}^{3+}$; while $v, v^{\prime \prime}, v^{\prime \prime \prime}, u, u^{\prime \prime}$, and $u^{\prime \prime \prime}$ are the characteristic peaks of $\mathrm{Ce}^{4+}$ ions. Similar peak fitting was also done for the XPS spectra of $6 \mathrm{~nm}$ and $30 \mathrm{~nm}$ cerium oxide nanoparticles (not shown). The peak positions for all the samples are listed in Table I. A semiquantitative analysis of the integrated peak area can provide the concentration of $\mathrm{Ce}^{3+}$ ions in the synthesized nanoparticles. It can be calculated as: ${ }^{10}$
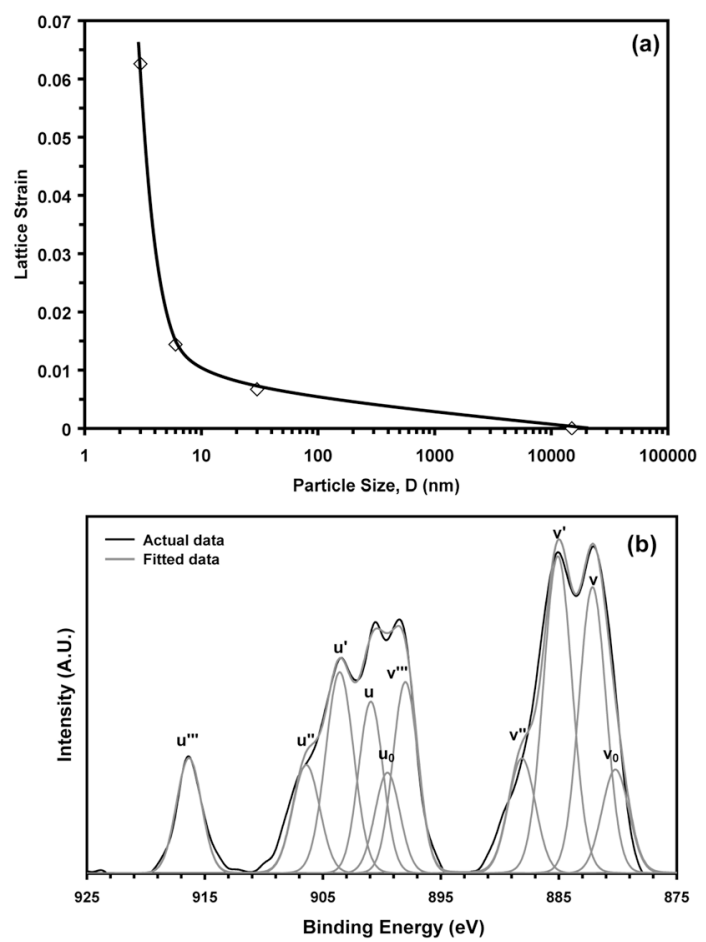

FIG. 3. (a) Semilog plot of the lattice strain as a function of the particle size. (b) Representative peak-fitted XPS spectrum of Ce $(3 d)$. 
TABLE I. XPS binding energies of individual peaks of the $\mathrm{Ce}(3 d)$ spectrum for different $\mathrm{CeO}^{2}$ nanoparticles samples.

\begin{tabular}{|c|c|c|c|c|c|c|c|c|c|c|}
\hline \multirow[b]{2}{*}{$\begin{array}{c}\text { Particle } \\
\text { size }\end{array}$} & \multicolumn{5}{|c|}{$\mathrm{Ce} \quad\left(3 d_{5 / 2}\right)$} & \multicolumn{5}{|c|}{$\mathrm{Ce} \quad\left(3 d_{3 / 2}\right)$} \\
\hline & $v_{0}$ & $v$ & $v^{\prime}$ & $v^{\prime \prime}$ & $v^{\prime \prime \prime}$ & $u_{0}$ & $u$ & $u^{\prime}$ & $u^{\prime \prime}$ & $u^{\prime \prime \prime}$ \\
\hline $3 \mathrm{~nm}$ & 880.20 & 882.10 & 885.00 & 888.10 & 898.00 & 899.50 & 900.90 & 903.50 & 906.40 & 916.35 \\
\hline $6 \mathrm{~nm}$ & 880.00 & 882.10 & 885.00 & 888.10 & 897.90 & 899.20 & 900.80 & 903.40 & 906.80 & 916.35 \\
\hline $30 \mathrm{~nm}$ & 880.40 & 881.90 & 882.80 & 888.30 & 897.90 & 899.60 & 900.60 & 903.30 & 907.20 & 916.20 \\
\hline
\end{tabular}

$\left[\mathrm{Ce}^{3+}\right]=\frac{A_{v 0}+A_{v^{\prime}}+A_{u 0}+A_{u^{\prime}}}{A_{v 0}+A_{v^{\prime}}+A_{u 0}+A_{u^{\prime}}+A_{v}+A_{v^{\prime \prime}}+A_{v^{\prime \prime \prime}}+A_{u}+A_{u^{\prime \prime}}+A_{u^{\prime \prime \prime}}}$,

where $A_{i}$ is the integrated area of peak " $i$."

Table II lists the concentration of $\mathrm{Ce}^{3+}$ present in all of the samples. It shows that the concentration of $\mathrm{Ce}^{3+}$ increases with a decrease in particle size of nanoceria. This can be attributed to higher oxygen vacancies in the smaller particles. Higher values of $\mathrm{Ce}^{3+}$ ions lead to a larger lattice strain and, subsequently, an increase in the lattice parameter of the particles. The correlation between the XPS and XRD results authenticates that the concentration of $\mathrm{Ce}^{3+}$ ions is proportional to lattice parameter increase.

A correlation between the particle size and the lattice parameter of nanoceria has been established. The XRD and XPS analysis showed an increase in the lattice strain and the concentration of $\mathrm{Ce}^{3+}$ ions in nanoceria as a function of the

TABLE II. Concentration of $\mathrm{Ce}^{3+}$ as a function of nanoceria particle size calculated using Eq. (4).

\begin{tabular}{cccc}
\hline \hline Particle size & $3 \mathrm{~nm}$ & $6 \mathrm{~nm}$ & $30 \mathrm{~nm}$ \\
\hline Concentration of $\mathrm{Ce}^{3+}$ & 0.44 & 0.29 & 0.17 \\
\hline \hline
\end{tabular}

particle size. The increase in the lattice parameter of nanoceria with decreasing particle size was attributed to the lattice strain induced by the creation of oxygen vacancies and the introduction of $\mathrm{Ce}^{3+}$ ions in the cerium oxide crystal structure.

The nanotechnology research is funded by NSF CTS 0350572, EEC: 0453436, NASA Glenn (NAG 32751), ONR Young Investigator Award (ONR: N000140210591), DOE SBIR Phase IDE-FG02-04ER83994.

${ }^{1}$ H. Gleiter, Prog. Mater. Sci. 33, 223 (1989).

${ }^{2}$ R. J. Gorte, H. Kim, and J. M. Vohs, J. Power Sources 106, 10 (2002).

${ }^{3}$ S. Yabe and T. Sato, J. Solid State Chem. 171, 7 (2003).

${ }^{4}$ P. Jasinski, T. Suzuki, and H. U. Anderson, Sens. Actuators B 94, 222 (2003).

${ }^{5}$ E. Mamontov, W. Dmowski, T. Egami, and C. C. Kao, J. Phys. Chem. Solids 61, 431 (2000).

${ }^{6}$ S. Patil, S. C. Kuiry, S. Seal, and R. Vanfleet, J. Nanopart. Res. 4, 433 (2002).

${ }^{7}$ J. C. Conessa, Surf. Sci. 339, 337 (1995).

${ }^{8}$ H. Zou, Y. S. Lin, N. Rane, and T. He, Ind. Eng. Chem. Res. 43, 3019 (2004).

${ }^{9}$ C. W. Jones, Applications of Hydrogen Peroxide and Derivatives, edited by J. H. Clark, (Royal Society of Chemistry, Cambridge, UK, 1999), Chap. 2, pp. 37-78.

${ }^{10} \mathrm{~S}$. Seal and T. Barr, Experimental Methods in the Physical Sciences, edited by H. Singh Nalwa (Academic, New York, 2001), Chap. 2, pp. 111-190. 